\title{
Chronic obstructive pulmonary disease combined with interstitial lung disease
}

\section{Running title: Chronic obstructive pulmonary disease with ILD}

Authors: Joon Young Choi, MD, $\mathrm{PhD}^{1}$; Jin Woo Song, $\mathrm{MD}, \mathrm{PhD}^{2}$; Chin Kook Rhee, MD, $\mathrm{PhD}^{3}$

${ }^{1}$ Division of Pulmonary and Critical Care Medicine, Department of Internal Medicine, Incheon St. Mary’s Hospital, College of Medicine, The Catholic University of Korea, Seoul 06649, Republic of Korea

${ }^{2}$ Division of Pulmonary and Critical Care Medicine, Asan Medical Center, University of Ulsan College of Medicine, Seoul 05505, Republic of Korea

${ }^{3}$ Division of Pulmonary and Critical Care Medicine, Department of Internal Medicine, Seoul St. Mary’s Hospital, College of Medicine, The Catholic University of Korea, Seoul 06649, Republic of Korea

Address for correspondence: Chin Kook Rhee, MD, PhD

Division of Pulmonary, Allergy and Critical Care Medicine, Department of Internal Medicine, Seoul St. Mary's Hospital, College of Medicine, The Catholic University of Korea, 222 Banpodaero, Seochogu, Seoul 06591, Republic of Korea 
Fax: +82 25993589

E-mail : chinkook77@gmail.com

Keywords: Chronic obstructive lung disease, Interstitial lung disease, Interstitial lung abnormalities, Combined pulmonary fibrosis and emphysema.

\section{Author Contributions}

Conceptualization: Choi JY, Rhee CK (for Joon Young Choi and Chin Kook Rhee)

Methodology: Rhee CK, Song JW (for Jin Woo Song)

Investigation: Choi JY, Song JW, Rhee CK

Writing-original draft preparation: Choi JY

Writing-review and editing: Choi JY, Song JW, Rhee CK

Approval of final manuscript: All authors 


\begin{abstract}
Although chronic obstructive pulmonary disease (COPD) and interstitial lung disease (ILD) have distinct clinical features, both diseases may coexist in a patient because they share similar risk factors such as smoking, male sex, and old age. Patients with both emphysema in upper lung fields and diffuse ILD are diagnosed with combined pulmonary fibrosis and emphysema (CPFE), which causes substantial clinical deterioration. Patients with CPFE have higher mortality compared with patients who have COPD alone, but results have been inconclusive compared with patients who have idiopathic pulmonary fibrosis (IPF). Poor prognostic factors for CPFE include exacerbation, lung cancer, and pulmonary hypertension. The presence of interstitial lung abnormalities, which may be an early or mild form of ILD, is notable among patients with COPD, and is associated with poor prognosis. Various theories have been proposed regarding the pathophysiology of CPFE. Biomarker analyses have implied that this pathophysiology may be more closely associated with IPF development, rather than COPD or emphysema. Patients with CPFE should be advised to quit smoking and undergo routine lung function tests, and pulmonary rehabilitation may be helpful. Various pharmacologic agents and surgical approaches may be beneficial in patients with CPFE, but further studies are needed.
\end{abstract}




\section{Introduction}

Chronic obstructive pulmonary disease (COPD) is a heterogeneous disease characterized by chronic respiratory symptoms accompanied by persistent airflow limitation ${ }^{1}$. Emphysematous changes in the lung are frequently observed in patients with COPD because of alveolar wall destruction due to toxic inhalation (e.g., cigarette smoke), causing distal airspace enlargement ${ }^{2,3}$. Consequently, maximal expiratory airflow is decreased by loss of elastic recoil of emphysematous lung ${ }^{3}$. Inflammation and peribronchial fibrosis in small conducting airways ( $<2 \mathrm{~mm}$ in diameter), referred to as small airway disease (SAD), are also major pathologic changes in COPD ${ }^{3}$. Additionally, interstitial lung disease (ILD) is a cluster of diseases characterized by inflammatory and fibrotic infiltration of alveolar septa that cause substantial changes in the alveolar epithelium and capillary endothelium ${ }^{3}$. Both COPD and ILD have distinct features, but may coexist in a single patient because they share some similar risk factors (e.g., old age, male sex, and tobacco exposure) ${ }^{1,4-8}$. In this review, we discuss current issues regarding the clinical view of ILD in patients with COPD with respect to prevalence, prognosis, pathophysiology, management, and pharmacologic treatments.

\section{Prevalence}

Cottin et al. first proposed the disease entity "combined pulmonary fibrosis and emphysema” (CPFE), which was defined as diffuse interstitial fibrosis along with emphysematous changes in upper lobes ${ }^{9}$. Interstitial changes vary in patients with CPFE, such that most are unclassifiable, one-third have the usual interstitial pneumonia pattern, and one-fifth constituted classifiable ${ }^{10}$. Among classifiable ILD, connective tissue diseases 
(CTD)-ILD composites nearly half of the patients and other classifiable ILD including idiopathic non-specific interstitial pneumonia, eosinophilic pneumonia, chronic hypersensitivity pneumonia, desquamative interstitial pneumonia/respiratory bronchiolitisILD composite the other half. In a multicenter retrospective study analyzing 34 CPFE patients with CTD-ILD (CTD-CPFE), 53\% of patients had rheumatoid arthritis (RA), 29\% had systemic sclerosis, $23 \%$ had mixed or overlap CTD and $12 \%$ had other CTDs ${ }^{11}$. A pooled prevalence of CTD-ILD associated with systemic sclerosis in three previous studies was reported to be $13.4 \%{ }^{12-15}$. The prevalence of emphysema ( $>5 \%$ in high-resolution computed tomography (HRCT) was reportedly $13.4-25.4 \%$ and COPD was evident in 9.2\% of patients with idiopathic pulmonary fibrosis (IPF) ${ }^{16-18}$. Furthermore, among patients with rheumatoid arthritis-related ILD, emphysema was found in $27 \%$ of non-smokers and $76 \%$ of smokers ${ }^{19}$.

Interstitial lung abnormalities (ILA) are defined as increased lung densities on chest computed tomography (CT) images of patients without previous history of ILD ${ }^{20-22}$. Because these changes in the lungs have similar but milder clinical characteristics than ILD, they are presumed to be early or mild manifestations of ILD ${ }^{20}$. These changes reportedly coexist in $13.5 \%$ of patients with COPD ${ }^{23}$.

\section{Pathophysiology and biomarkers}

The pathogenesis of CPFE has been still largely unknown, and previous studies have suggested possible pathophysiology of the disease (Fig. 1). Because IPF and emphysema share similar risk factors (e.g., cigarette smoking), simultaneous or successive emphysema and fibrosis may develop. In patients with simultaneous development, the locations of emphysema and fibrosis may be distributed in similar regions of the lung ${ }^{24}$. Basal lung 
fibrosis has also been suggested to proceed initially along upper lung field tracts, thereby promoting the progression of emphysema ${ }^{9}$. Some studies have speculated that autoimmune features or gastroesophageal reflux disease caused by smoking habits may affect CPFE progression $^{5,25,26}$.

Some genetic backgrounds have been studied as potential predisposing factors for CPFE progression ${ }^{27,28}$. There have been reported that some genes, such as FAM13A and TERT gene, are associated with both COPD and IPF progression ${ }^{29-32}$. A recent study conducted by Guzman-Vargas et al. investigated the association of several genes, including FAM13A, TERT, DSP and TOLLIP, which are reported to be related to IPF progression ${ }^{33}$. The study has shown that rs2736100C allele in TERT gene and specific genotype of rs2076295 (DSP) are associated with increased risk of CPFE. The ATP-binding cassette subfamily A member 3 (ABCA3) and surfactant protein-C (SFTPC) genes have important roles in the maintenance of lung surfactant homeostasis, and a few case reports have implied associations between CPFE and mutations in those genes ${ }^{34,35}$. A recent study by Kinjo et al. investigated the Gly82Ser mutation in the advanced glycosylation end-product specific receptor (AGER) gene in 111 patients with CPFE and 337 patients with COPD in Japanese patients ${ }^{36}$. It revealed that the AGER gene mutation leads to RAGE pathway inhibition, which may be associated with lung fibrosis in patients with CPFE.

Efforts to reveal immunological and inflammatory mechanisms of CPFE progression have included several studies of biomarkers associated with the disease. Cornwell et al. studied explanted lung tissue from patients who died of lethal trauma. They categorized lung tissue into emphysema only, IPF, CPFE, and healthy control groups, then compared levels of 34 inflammatory biomarkers ${ }^{37}$. Regional comparisons of biomarkers showed no significant differences among groups (i.e., emphysema, IPF, or CPFE), except in the level of CCL22. 
Additional comparisons of biomarkers between groups revealed four clear categories: biomarkers elevated in emphysema alone (interleukin [IL]-6, CXCL10, CCL2, IL-10, and interferon- $\gamma$ ); biomarkers reduced in emphysema alone (IL-17A, IL-13, matrix metalloproteinase [MMP] 1, MMP13, MMP2, CCL24, and lysyl oxidase); biomarkers that were similar among emphysema, IPF, and CPFE, but different from the healthy control group (sCD14, CCL5, tumor necrosis factor [TNF] RII, SP-D, ST2, IL-1 $\beta$, IL-4, IL-5, CXCL8, and $\mathrm{TNF} \alpha$ ); and biomarkers with a mixed pattern that did not fit any other categories. These results suggest that the levels of inflammatory proteins are generally comparable between IPF and CPFE, but distinct features are present in emphysema. These results were also consistent with the findings of previous studies ${ }^{38-41}$. Therefore, the immunological pathogenesis of CPFE may be more closely associated with IPF development.

Klebs von den Lungen-6 (KL-6) is a high-molecular-weight glycoprotein that is strongly expressed on type II alveolar pneumocytes and bronchiolar epithelial cells. It is an important marker of ILD and is associated with disease severity, progression, and survival; notably, it promotes pulmonary fibroblast migration and proliferation ${ }^{42-45}$. Because of this association with ILD, some studies have investigated relationships with fibrotic changes in patients with COPD. In asthma-COPD overlap, patients with a history of smoking and older age have more frequent ILA ${ }^{46}$. These patients with asthma-COPD overlap and ILA showed higher levels of KL-6, compared with patients with asthma-COPD overlap who lacked ILA. The clinical significance of KL-6 has also been investigated in patients with CPFE. Chiba et al. revealed that KL-6 and SP-D were both correlated with lung volume and composite physiologic index among patients with CPFE. Furthermore, a high level of KL-6 in patients with CPFE is reportedly a strong predictor of frequent AE-IPF, similar to its role in patients with IPF ${ }^{47,48}$. These results indicate that KL-6 is an important biomarker related to fibrotic changes and disease prognosis in patients with CPFE. 


\section{Radiologic features}

HRCT is considered to be the most important diagnostic tool of CPFE, as its definition is based on radiologic features. Although it was initially suggested as coincidence of upper lung emphysema with features of diffuse interstitial lung fibrosis, consecutive studies have used this term heterogeneously (Fig 2) ${ }^{9,49}$. In total of 72 studies with CPFE patients, $60 \%$ of studies have defined CPFE with emphysema located in the upper zone, and $40 \%$ with emphysema in all location or did not specify its location ${ }^{49}$. Also, $72 \%$ of studies have enrolled patients with emphysema by any extent, but $28 \%$ of studies have limited by specific threshold, including emphysema presented $\geq 10 \%$ of lung volume (9 studies), $\geq 5 \%$ (4 studies) and $\geq 25 \%$ (4 studies). Majority of the studies (97\%) have evaluated the extent of lung fibrosis visually.

Emphysematous lesions of CPFE can be presented as centrilobular, paraseptal or mixed lesion of both type. Among these manifestations, there were discrepancies between studies on majority type of emphysema; centrilobular ${ }^{50-52}$, paraseptal ${ }^{9,53-55}$ or mixed type ${ }^{10,56}$ were reported to be most common type of emphysema in different studies. Regarding fibrotic area of CPFE, usual interstitial pneumonia has been shown to be the most common histological morphology in previous studies ${ }^{9,57}$. Honeycombing, reticular opacities, traction bronchiectasis and ground-glass opacities (GGO) were most frequently seen in HRCT findings ${ }^{9}$. Distribution pattern of CPFE were described as three patterns; (1) area of emphysema and fibrosis distributed in completely separated pattern (emphysema positioned 
in the upper zones and fibrotic area in the basal zones), (2) progressive transition of diffuse upper zone emphysema to a zone of transition between bullae and honeycombing, (3) paraseptal emphysema positioned within fibrotic areas ${ }^{58}$.

Thick-walled large cysts (TWLCs), which were defined as cysts with diameter $\geq 2 \mathrm{~cm}$ surrounded by a wall $\geq 1 \mathrm{~mm}$ thick, were proposed as a unique feature of CPFE ${ }^{11,55}$. Inomata et al. performed an autopsy study of 22 CPFE patients in comparison with 8 IPF and 17 emphysema-alone patients. TWLCs were only presented in CPFE patients, and neither IPF nor emphysema-alone patients showed this lesion ${ }^{55}$. In this study, total of $72.7 \%$ patients were shown to have TWLCs in CPFE patients, radiologically and pathologically (68.8\% in upper lobes and $62.5 \%$ in lower lobes, radiologically). TWLCs were found in the centriacinar/centrilobular lesions, involving one or more acini, membranous and respiratory bronchioles, with alveolar destruction, dense wall fibrosis and occasional fibroblastic foci. These lesions were shown to be presented belong upper paraseptal emphysema near chest wall or shown within zone of fibrosis ${ }^{59}$. It may be caused by development of lung fibrosis within emphysematous lesions, and expanded by retraction induced by fibrotic process ${ }^{28,58}$. Although TWLCs are exclusively presented rather than IPF or emphysema-alone patients, differential diagnosis including lung abscess, cancer, mycobacterial/fungal infections should be considered ${ }^{60}$.

\section{Prognosis}

Prognosis of CPFE

Although there are no exact diagnostic criteria including the extent or localization of 
emphysema, the clinical implications of CPFE (determined using various definitions) are reportedly substantial ${ }^{49,61}$. A previous study reported that 5-year survival was $54.6 \%$ and median survival was 6.1 years in patients with $\mathrm{CPFE}^{9}$. Notably, accompanying pulmonary fibrosis in patients with emphysema resulted in five-fold greater mortality risk, compared with nonmalignant patients who did not have pulmonary fibrosis (Fig. 3). ${ }^{50}$. However, there are conflicting results regarding mortality in patients with CPFE and patients with IPF alone: some studies reported no significant difference in mortality ${ }^{16,17,62-64}$, while others reported that mortality was higher in CPFE groups ${ }^{56,65-68}$ or lower in CPFE groups ${ }^{69,70}$. In a metaanalysis performed by Koo et al., higher mortality was noted in patients with CTD-CPFE, compared to those without CTD-ILD with emphysema ${ }^{12}$. Various studies that analyzed factors associated with CPFE was shown in Table 1.

The most important factors that influence CPFE prognosis are acute exacerbation, pulmonary hypertension, and the presence of lung cancer ${ }^{5,66,71,72}$ (Fig. 3). Previous studies have reported that the prognosis of acute exacerbation is favorable, and that acute exacerbation is less frequent in patients with CPFE than in patients with IPF. However, it may have lethal consequences and careful monitoring is needed ${ }^{73,74}$. Zantah et al. stratified exacerbation events in patients with CPFE into acute exacerbation of COPD (AE-COPD) and acute exacerbation of IPF (AE-IPF) ${ }^{74}$. AE-COPD comprised clinical symptoms of airway obstruction with radiologic findings such as airway wall thickening, mucus impaction, atelectasis, consolidation, and mediastinal adenopathy. That study only included severe exacerbation, which was defined by events that led to hospitalization, as defined in the Global Initiative for Chronic Obstructive Lung Disease (GOLD) 2018 guideline. By contrast, AEIPF comprised acute respiratory deterioration that led to hospitalization and the use of highdose corticosteroids. Furthermore, it involved radiologic findings of new lesions (e.g., ground-glass opacities, interlobular septal thickening, and consolidation). The authors 
analyzed the prevalence and prognosis of exacerbation events, as well as the applications of mechanical ventilation or extracorporeal membrane oxygenation. Exacerbation was more prevalent as AE-IPF, rather than AE-COPD (14.1\% vs. 11.7\%, p < 0.01), and all mortalities were related to AE-IPF. Applications of mechanical ventilation or extracorporeal membrane oxygenation were more frequently performed in patients with AE-IPF than in patients with AE-COPD. Therefore, in patients with CPFE who exhibit clinical signs of exacerbation, identification of exacerbation type may be important because AE-IPF requires closer observation and earlier intervention.

Previous studies have shown that pulmonary hypertension is an important poor prognostic factor for CPFE. In a pivotal study, Cottin et al. performed survival analysis of 61 patients with CPFE. They showed that the presence of pulmonary hypertension was significantly associated with poor survival (HR: 4.03, $\mathrm{p}=0.03$ ) ${ }^{9}$. Patients with pulmonary hypertension at diagnosis had a mean survival of 4.8 years and 5 -year survival of $25 \%$, whereas patients without pulmonary hypertension had a mean survival of 9.1 years and 5year survival of $75 \%$. In another study, Mejia et al. reported that low functional vital capacity (FVC $<50 \%$ predicted, HR: 2.6, $\mathrm{p}=0.02$ ) and severe pulmonary hypertension (systolic pulmonary artery pressure $\geq 75 \mathrm{mmHg}$, HR: 2.25, $\mathrm{p}=0.02$ ) were important clinical factors associated with poor survival ${ }^{65}$. Patients with CPFE who were diagnosed with pulmonary hypertension exhibited 1-year survival of $60 \%{ }^{75}$. Overall, pulmonary hypertension is reportedly observed in 29-68\% of patients with CPFE ${ }^{9,71,75,76}$.

Because both emphysema and IPF have been identified as independent risk factors for lung cancer, CPFE is presumably a major risk factor for lung cancer development. Furthermore, most patients with CPFE have a history of smoking, and therefore an association may exist between CPFE and lung cancer ${ }^{63,77}$. In a retrospective study of 47 
patients with CPFE, 22 patients (46.8\%) had concomitant lung cancer ${ }^{54}$. Compared with patients who had emphysema alone, patients with CPFE and patients with IPF had greater risks of lung cancer development (adjusted HR: $4.62 \quad[\mathrm{p}<0.01], 4.15$ [p = 0.046], respectively). The difference between CPFE and IPF groups was not statistically significant ${ }^{78}$.

Although lung cancer itself may have severe consequences, it also contributes to poor disease outcomes in patients with CPFE. Oh et al. analyzed risk factors for acute exacerbation in 227 patients with CPFE ${ }^{79}$. They identified the presence of lung cancer (HR: 3.274, $\mathrm{p}<0.01$ ), as well as sex, age, and physiology (GAP) score (HR: 1.434, p=0.02) as significant risk factors for acute exacerbation. Furthermore, the coexistence of lung cancer is associated with increased mortality. Moon et al. compared patients with CPFE and patients with IPF, all of whom had been diagnosed with non-small cell lung cancer, and found that patients with CPFE had a significantly greater rate of acute exacerbation (HR: 2.26, $p=0.029$ ) 80. Furthermore, Usui et al. retrospectively reviewed 1143 patients with lung cancer to compare clinical outcomes between patients with underlying CPFE and patients with underlying emphysema. The median overall survival of patients with CPFE was 10.8 months, which was worse than the survival of patients with emphysema (21.9 months) or the survival of patients without emphysema or fibrosis (54.0 months).

The prognostic impact of the proportion of abnormal lesions has also been studied in patients with CPFE. Suzuki et al. showed that an increased proportion of abnormal area (i.e., sum of low attenuation area [pixels $<-950$ Hounsfield units, representing emphysema] and high attenuation area [pixels $>-700$ Hounsfield units, representing interstitial fibrosis]) in chest CT was significantly associated with frequent hospitalization in patients with CPFE ${ }^{51}$. Nemeto et al. analyzed fibrotic area alone in patients with CPFE, which revealed that patients with a higher proportion of fibrosis had higher mortality, more frequent exacerbations, worse 
lung function trajectories, and more rapid CPFE progression ${ }^{81}$. Malli et al. analyzed CPFE patients of a Greek cohort, and revealed that ILD extent of more than 30\% was associated with poor survival ${ }^{76}$. In contrast, Jacob et al. analyzed 272 IPF patients, and reported that presence or extent of emphysematous area in volumetric chest CT image were not associated with patients' survival ${ }^{82,83}$. Thus, revelation of abnormal lesion in CPFE patients is important in predicting the disease prognosis, and use of late gadolinium enhanced thoracic magnetic resonance imaging (LGE-MRI) may have a role in differentiation from pure emphysema ${ }^{84}$.

\section{Prognosis of ILA in COPD patients}

Previous studies have reported that ILA is presented in $8 \%$ of smokers and $13.5 \%$ of patients with COPD ${ }^{21,23}$. Because it is associated with decreased lung volume ${ }^{21,85}$, ILD progression ${ }^{86}$, and increased mortality ${ }^{20,85,86}$, in combination with a genetic background similar to the background in patients with IPF ${ }^{87}$, ILA is presumed to be an earlier or milder form of ILD ${ }^{49}$. Furthermore, ILA patterns are found in considerable numbers of patients with COPD, and thus the clinical significance of ILA has been studied in patients with COPD (Table 1).

Putman et al. analyzed the data of four major cohort studies including the Framingham Heart Study, AGES-Reykjavik study, COPDGene study, and ECLIPSE study ${ }^{20}$. Among 11,691 patients enrolled in these studies, 868 (7.4\%) patients had ILA in their CT images. Analyses of all-cause mortality in each cohort showed that ILA was associated with higher mortality (hazard ratio [HR]: 2.7 [95\% CI: 1.1-6.5], 1.3 [95\% CI: 1.2-1.4], 1.8 [95\% CI: 1.12.8], 1.4 [95\% CI: 1.1-2.8], respectively). Considering that many patients in the COPDGene study and all patients in the ECLIPSE study had COPD, the presence of ILA is presumably an important risk factor for death in patients with COPD. Additionally, the presence of ILA had a significant effect on mortality, regardless of correction for the volumetric proportion of 
emphysema.

Ash et al. performed a follow-up study with COPDGene cohort data, which investigated the clinical effects of ILA in patients with COPD ${ }^{22}$. They identified emphysema and ILA features in patients' chest CT images, using an objective CT analysis tool, then comprehensively analyzed their associations with lung function, health-related quality of life, exercise capacity, and mortality. Compared with patients who had emphysema alone, patients who had both emphysema and ILA demonstrated a higher percent of predicted forced expiratory volume in $1 \mathrm{~s}$ (FEV1) and a lower percent predicted diffusing capacity of lung for carbon monoxide (DLCO). However, there were no significant differences in terms of forced vital capacity (FVC) between the two groups. Feldhaus et al. also showed that high attenuated volume in quantitative CT was associated with a profound reduction of DLCO ${ }^{88}$. Moreover, Ash et al. showed that exercise capacity (measured with the 6-min walking test), healthrelated quality of life (evaluated with St. George's Respiratory Questionnaire score), and mortality were all unfavorable in patients who had both emphysema and ILA ${ }^{22}$. The impact of emphysema spatial capacity in mortality was higher in patients with ILA, compared with patients who had emphysema alone $(\mathrm{p}=0.04)$. Although previous mentioned studies indicate poor prognosis of ILA in COPD patients, a previous study showed that the presence of ILA was associated with a lower exacerbation rate in patients with COPD ${ }^{89}$.

Prognosis of COVID-19 in CPFE patients

COVID-19, which is caused by SARS-CoV-2 virus, has been affected 170 million patients and caused more than 3.5 million death worldwide by June $2021^{90}$. Among patients with COVID-19 disease, comorbidities such as chronic respiratory diseases, cardiovascular diseases, diabetes and cancer are reported to be associated with severe course of the disease 91-94. Since there have been no data investigating prognosis of COVID-19 in CPFE patients, 
its prognosis may be assumed by reviewing data of each disease component. Accompanying ILD in COVID-19 was shown to be associated with higher mortality ${ }^{95,96}$. Presence of IPF rather than non-IPF ILD, old age, male sex, obesity, severe underlying ILD and low FVC were associated with poor survival in those patients ${ }^{95,97}$. In contrast, conflicting results have been reported regarding impact of COPD in COVID-19; some data shows that it is associated with risk of hospitalization and mortality ${ }^{98,99}$, while some studies present no significant association of COPD in risk of hospitalization, ICU admission and mechanical ventilation, and mortality ${ }^{100-103}$.

\section{Management}

\section{Non-pharmacologic treatments}

\section{Smoking cessations}

The most important aspect during management of patients with CPFE is smoking cessation, because smoking is the most influential risk factor for both emphysema and IPF. Nearly all patients with CPFE have a history of smoking. Moreover, patients who continue to smoke show significant radiologic progression of CPFE lesions, compared with patients who quit smoking ${ }^{77,104}$. Patients who continue to smoke should be prescribed individualized counselling and drug therapy (e.g., nicotine replacement therapy, bupropion, or varenicline) 105. Furthermore, because the presence of ILA is also associated with a history of smoking, smoking cessation should be recommended for patients with ILA to improve their prognoses 21

\section{Routine pulmonary function tests}

Previous studies have reported exceptional lung function test outcomes in patients with CPFE, and therefore routine follow-up involving lung function tests should be performed in 
these patients because the results may reflect disease progression and prognosis. In patients with CPFE, lung function test results are typically regarded as normal or sub-normal, especially in terms of lung volume and FEV1/FVC. This is the result of counterbalancing opposite effects on lung compliance and elastance of interstitial fibrosis and COPD ${ }^{24,77}$. However, DLCO is disproportionately reduced because both processes cause alveolar capillary membrane disruption ${ }^{24,106,107}$. Longitudinal analysis of 5-year lung function data in patients with CPFE was performed by Kitaguchi et al. ${ }^{108}$. Notably, annual reduction of vital capacity and FVC were significantly greater in patients with CPFE than in patients with COPD; FEV1/FVC were improved in patients with CPFE during the follow-up period. However, DLCO and DLCO/vital capacity were more rapidly reduced in patients with CPFE than in patients with COPD. FEV1 is usually preserved in patients with CPFE because the traction effects of interstitial fibrosis prevent small airway collapse during expiration ${ }^{12,109}$. However, patients with CPFE involving rapid FEV1 decline had higher mortality ${ }^{110}$. Accordingly, assessment of DLCO and FEV1 in patients with CPFE may be important for monitoring disease progression and predicting patient prognosis.

In addition, the presence of ILA is associated with reduced lung volume in patients who smoke, which may result in pseudonormalization of FEV1/FVC in patients with COPD. Accordingly, these patients may exhibit preserved ratio impaired spirometry (PRISm) (FEV1/FVC $\geq 0.7$ and FEV1 $<80 \%$ predicted) according to spirometric assays ${ }^{21}$. Young et al. performed 5-year longitudinal analysis of the COPDGene study and revealed that 36\% of patients with PRISm progressed from GOLD 2 to GOLD $4{ }^{111}$. Accordingly, clinicians should perform routine lung function tests in patients with PRISm.

\section{Pulmonary rehabilitations}

There is increasing evidence regarding pulmonary rehabilitation in patients with 
chronic respiratory diseases ${ }^{112}$. In the GOLD 2021 guideline, pulmonary rehabilitation is recommended in patients with GOLD B-D COPD ${ }^{1}$. It has been shown to relieve respiratory and systemic symptoms, improve health-related quality of life and exercise tolerance, and reduce the hospitalization rate and mortality in patients with COPD ${ }^{113}$. Furthermore, positive outcomes have been reported in patients with ILD. In particular, pulmonary rehabilitation improves dyspnea, health-related quality of life, and exercise tolerance, although the magnitudes of benefits were lower than in patients with COPD ${ }^{114-118}$. Because two components of CPFE (COPD and ILD) are improved by pulmonary rehabilitation, this treatment may have favorable impacts on patients with CPFE. Tomioka et al. performed a single-center retrospective study to compare the effects of 3-week pulmonary rehabilitation between patients with CPFE and patients with COPD ${ }^{119}$ They measured lung function, exercise capacity using the 6-min walking test, and health-related quality of life using the Short Form-36 (SF-36) questionnaire. Both groups showed lung function improvement, but 6-min walking test results were only improved in patients with COPD. In the SF-36 test, patients with CPFE showed improved physical function $(p=0.015)$ but worsened social functioning $(\mathrm{p}=0.044)$, whereas patients with COPD showed improvement in half of the subscales in the SF-36 questionnaire. There were significant differences in SF-36 score between patients with CPFE and patients with COPD in subscales of $\Delta$ vitality $(-6.3 \pm 22.4$ in CPFE vs. $11.3 \pm 21.1$ in COPD, $\mathrm{p}=0.009)$ and $\Delta$ social functioning $(-18.8 \pm 34.2$ in CPFE vs. $5.3 \pm 35.9$ in COPD, $\mathrm{p}=0.027)$. Although the CPFE group showed a reduced benefit of pulmonary rehabilitation, compared with the COPD group, this treatment remains helpful in terms of lung function and physical function in patients with CPFE. However, further prospective and multicenter studies are needed to confirm the positive effect of pulmonary rehabilitation in patients with CPFE. 


\section{Pharmacologic treatments}

\section{Inhalers}

Many patients with CPFE use bronchodilator and inhaled corticosteroid (ICS) therapies in real-world clinical practice, but few clinical studies have assessed the efficacies of those drugs in patients with CPFE ${ }^{66}$. Dong et al. conducted a prospective cohort study of patients with CPFE, which investigated clinical efficacy and safety profiles of ICS/long-acting betaagonist (LABA) therapies by grouping patients into ICS/LABA users and non-users ${ }^{120}$. At the 1-year follow up, ICS/LABA users showed increases in FEV1\%, FVC\%, and DLCO\% of $11.2 \%, 13.5 \%$, and $12.8 \%$, respectively. By contrast, non-users showed decreases of $14.2 \%$, $16.8 \%$, and $21.3 \%$, respectively. Furthermore, radiologic findings also significantly improved in the ICS/LABA user group, whereas they worsened in the non-user group. Favorable outcomes have been reported in terms of acute exacerbation rates, but no significant differences were found in safety profiles. However, because of the non-randomized nature of the study and small number of enrolled patients, additional research is needed to confirm the benefits of this drug.

According to the 2014 French Practical guidelines, patients with IPF are recommended to use inhaled bronchodilator therapy in the event of airway obstruction ${ }^{121}$. However, for most patients with IPF, FEV1/FVC is $>0.7$ regardless of emphysema, due to the FVCcounterbalancing effect of lung fibrosis. In these patients, the effect of bronchodilator is not clinically significant. However, in patients with SAD measured through impulse oscillometry parameters, bronchodilator use showed improvement in symptoms, FEV1, and forced expiratory flow at $25-75 \%$ of the pulmonary volume ${ }^{122,123}$. In the absence of SAD, bronchodilator therapy is ineffective. Furthermore, patients with emphysema should not use 
bronchodilator therapy, because the effect was not clinically significant in patients with emphysema alone. Because SAD may be an early phase of COPD, regardless of airway obstruction, bronchodilator use may be considered in patients with IPF who have SAD ${ }^{124,125}$.

\section{Antifibrotics}

Antifibrotic drugs, including pirfenidone and nintedanib, are known to impede disease progression in patients with IPF ${ }^{126-129}$. Pooled data analysis of three global phase 3 trials of CAPACITY trials (studies 004 and 006) and the ASCEND trial investigated 1-year outcomes of pirfenidone in patients with IPF ${ }^{127}$. In this pooled analysis, the authors concluded that pirfenidone treatment reduced the FVC decline rate $(-216 \mathrm{~mL}$ vs. $-363 \mathrm{~mL}$ per year, $\mathrm{p}<0.001$ ), enhanced progression-free survival by 38\%, and improved symptoms of dyspnea and 6-min walking distance, compared with the placebo group. Although the study only enrolled patients with FEV1/FVC $>0.70$, the authors performed a subgroup analysis of FVC decline regarding FEV1/FVC of $<0.80,0.80$ to $<0.85$, and $\geq 0.85$. Similar results were achieved with nintedanib, an intracellular tyrosine kinase inhibitor, in patients with IPF. The INPULSIS trials (i.e., two replicate, 52-week, randomized, placebo-controlled, double-blind phase III trials) compared the efficacy and safety of nintedanib in patients with IPF ${ }^{129}$. Treatment with $150 \mathrm{mg}$ of nintedanib twice daily in patients with IPF led to significant alleviation of FVC decline, compared with the placebo group $(-114.7 \mathrm{~mL}$ vs. $-239.9 \mathrm{~mL}$ per year, $\mathrm{p}<0.001$ ). As in previous studies regarding pirfenidone, the INPULSIS study enrolled patients with FEV1/FVC $>0.70$. In subgroup analysis of INPULSIS study data, nintedanib

alleviated FVC decline in both FEV1/FVC $>0.8$ and $\leq 0.8$ subgroups ${ }^{130}$. Moreover, nintedanib alleviated FVC decline, regardless of emphysema presence in baseline highresolution CT. These results imply that patients with IPF and airway obstruction or emphysema can benefit from both antifibrotic drugs. However, further studies are needed 
regarding patients with IPF who have FEV1/FVC $<0.70$ or different extents of emphysema according to quantitative assays.

Steroids and immunosuppressants

There have been no reports that proves efficacy of systemic steroids and immunosuppressants on CPFE patients. However, decision to use those drugs should be made regarding phenotype and disease status. As CTD-ILD have been shown to have potential beneficial effect with corticosteroids and immunosuppressant, those drugs should be considered to be applied in CPFE patients with CTD-ILD ${ }^{131,132}$. However, previous reports and guidelines presents limited role of systemic steroids or immunosupressants in COPD (emphysema) or IPF patients ${ }^{1,133}$. On the other hand, patients in exacerbation state of CPFE may need systemic steroids as it is both recommended in COPD-AE and IPF-AE ${ }^{1,133}$.

\section{Other adjuvant therapy}

Large proportions of patients with CPFE have been reported to exhibit dyspnea, and most of these patients require oxygen supplementation during a 5-year follow-up period ${ }^{63,77}$. In the advanced stages of chronic lung diseases such as CPFE, breathlessness is a considerable burden to patients and may not be sufficiently diminished despite comprehensive interventions ${ }^{134,135}$. Previous studies reported that the usage of morphine may be effective for relieving dyspnea symptoms, but other opioids have led to controversial outcomes ${ }^{136-138}$. Recently, several antidepressants have been studied for symptomatic relief in patients with chronic lung diseases. Mirtazapine, a noradrenergic and specific serotonergic antidepressant, was effective in treating chronic breathlessness in a multicenter, randomized, placebo-controlled, double-blind, feasibility trial ${ }^{139}$. Ninety-five percent of patients had 
either COPD or ILD, and all patients had a Modified Medical Research Council score $\geq 3$ at baseline. After randomization, the mirtazapine group consistently showed a lower numerical rating scale score in weekly measurements over 1 month, compared with the placebo group. Other antidepressants, including sertraline and paroxetine, showed promising results for breathlessness relief in some small clinical studies, but further investigations are needed ${ }^{140-}$ 143

Vasodilators for pulmonary hypertensions

Pulmonary vasodilator therapy for pulmonary hypertension in patients with CPFE is not recommended, because there is minimal evidence to support this approach ${ }^{144}$. The usage of pulmonary vasodilators may worsen V/Q mismatch and hypoxemia ${ }^{109}$. However, a recent case report indicated that the use of tadalafil led to improvements in pulmonary arterial compliance and exercise capacity ${ }^{145}$. The benefits of pulmonary vasodilators in pulmonary hypertension should be investigated in future studies. Overall, pharmacologic treatments that may play a role in patients with CPFE are summarized in Table 2.

\section{Surgical interventions}

Limited roles of surgical interventions have been presented in patients with CPFE. A case report presented a successful lung volume reduction surgery in CPFE patients, which resulted in improvements in dyspnea, lung function and exercise tolerance ${ }^{146}$. In patients with severe disease, lung transplantation should be considered as an ultimate treatment. Takahashi et al. performed a single-center retrospective cohort study and reported clinical outcomes of lung transplantation in CPFE patients ${ }^{147}$. Five-year survival of CPFE patients were $79.0 \%$, which was similar to IPF group, but more likely to suffer from primary graft 
dysfunction, acute cellular rejection and chronic lung allograft dysfunction.

\section{Limitations}

Our study is a narrative review that performed with unsystematic research, and thus may have limited value for making recommendations.

\section{Conclusion}

Concurrent interstitial fibrosis is often found in patients with COPD and patients with emphysema, because both diseases have strong relationships with cigarette smoking and old age. Patients with increased density in chest CT without a history of ILD are diagnosed with ILA. ILA is regarded as an early stage of ILD progression, and the presence of ILA has been associated with poor lung function, exercise capacity, health-related quality of life, and mortality in both patients with COPD and patients with emphysema. Furthermore, patients with diffuse interstitial fibrosis combined with upper emphysema are diagnosed with CPFE. The mortality of patients with CPFE is worse than the mortality of patients with emphysema alone, but results have been inconclusive when compared with patients who have IPF. Acute exacerbation, pulmonary hypertension, and lung cancer were most strongly associated with CPFE prognosis. Biomarker studies have suggested that the pathophysiology of CPFE is more closely associated with IPF, rather than COPD. For the management of patients with CPFE, smoking cessation is critical; routine lung function tests may be useful for monitoring disease progression. Pulmonary rehabilitation and drugs (e.g., ICS/LABA therapy, bronchodilator, anti-fibrotic agents, and antidepressants) have been recently proposed for use in disease control, but further investigations are needed. Surgical managements may have 
limited roles in severe disease.

Since the introduction of the disease entity called CPFE in 2005 by Cottin et al., numerous studies have been conducted to understand its clinical significance. There were several distinct features compared with ILD or emphysema alone especially in prognostic aspects. Therefore, clinicians should be aware of their clinical characteristics. However, most of the studies included small number of patients, and there were several discrepancies between study results. Further larger studies should be performed to fully understand its clinical implications. Also, there were little evidences on benefits of pharmacologic agents, which are needed to be studied in further studies. Patients with CPFE may be undertreated as pseudonormalization of lung function tests, who may be needed to be treated with COPD drugs including inhalers. In addition, as increasing performance of low dose chest CT, ILA have been more detected and recent evidences proved its clinical significance. Clinicians should be aware of these lesions as it may be associated with poor prognosis especially in emphysema or COPD patients.

\section{Acknowledgements}

None 


\section{Competing interests}

The authors declare that they have no competing interests.

\section{References}

1. Global Initiative for Chronic Obstructive Lung Disease. Global Strategy for the Diagnosis, Management and Prevention of COPD, Global Initiative for Chronic Obstructive Lung Disease 2021. Available from: https://goldcopd.org/wp-content/uploads/2020/11/GOLDREPORT-2021-v1.1-25Nov20_WMV.pdf. Accessed December 23, 2020.

2. Liu Z, Shi F, Liu JX, Gao CL, Pei MM, Li J, et al. Effect of the emphysema subtypes of patients with chronic obstructive pulmonary disease on airway inflammation and COTE index. Exp Ther Med 2018;16:4745-52.

3. V. Courtney Broaddus RJM, Joel D.Ernst, Talmadge E. King, Jr., Stephen C. Lazarus, John F. Murray, Jay A. Nadel, Arthur S. Slutsky, Michael B. Gotway. Murray \& Nadel's Testbook of Respiratory Medicine. Sixth Edition.

4. Huie TJ, Solomon JJ. Emphysema and pulmonary fibrosis: coincidence or conspiracy? Respirology 2013;18:1163-4.

5. Hage R, Gautschi F, Steinack C, Schuurmans MM. Combined Pulmonary Fibrosis and Emphysema (CPFE) Clinical Features and Management. Int J Chron Obstruct Pulmon Dis 2021;16:167-77.

6. Selman M, Martinez FJ, Pardo A. Why Does an Aging Smoker's Lung Develop Idiopathic Pulmonary Fibrosis and Not Chronic Obstructive Pulmonary Disease? Am J Respir Crit Care Med 2019;199:279-85.

7. Lederer DJ, Martinez FJ. Idiopathic Pulmonary Fibrosis. N Engl J Med 2018;378:1811-23.

8. Raghu G, Collard HR, Egan JJ, Martinez FJ, Behr J, Brown KK, et al. An official ATS/ERS/JRS/ALAT statement: idiopathic pulmonary fibrosis: evidence-based guidelines for diagnosis and management. Am J Respir Crit Care Med 2011;183:788-824.

9. Cottin V, Nunes H, Brillet PY, Delaval P, Devouassoux G, Tillie-Leblond I, et al. Combined pulmonary fibrosis and emphysema: a distinct underrecognised entity. Eur Respir J 2005;26:586-93.

10. Alsumrain M, De Giacomi F, Nasim F, Koo CW, Bartholmai BJ, Levin DL, et al. Combined pulmonary fibrosis and emphysema as a clinicoradiologic entity: Characterization of presenting lung fibrosis and implications for survival. Respir Med 2019;146:106-12.

11. Cottin V, Nunes $H$, Mouthon L, Gamondes D, Lazor R, Hachulla E, et al. Combined 
pulmonary fibrosis and emphysema syndrome in connective tissue disease. Arthritis Rheum 2011;63:295-304.

12. Koo BS, Park KY, Lee HJ, Kim HJ, Ahn HS, Yim SY, et al. Effect of combined pulmonary fibrosis and emphysema on patients with connective tissue diseases and systemic sclerosis: a systematic review and meta-analysis. Arthritis Res Ther 2021;23:100.

13. Antoniou KM, Margaritopoulos GA, Goh NS, Karagiannis K, Desai SR, Nicholson AG, et al. Combined Pulmonary Fibrosis and Emphysema in Scleroderma-Related Lung Disease Has a Major Confounding Effect on Lung Physiology and Screening for Pulmonary Hypertension. Arthritis Rheumatol 2016;68:1004-12.

14. Ariani $A$, Silva $M$, Bravi $E$, Parisi $S$, Saracco $M$, De Gennaro $F$, et al. Overall mortality in combined pulmonary fibrosis and emphysema related to systemic sclerosis. RMD Open 2019;5:e000820.

15. Champtiaux N, Cottin V, Chassagnon G, Chaigne B, Valeyre D, Nunes $H$, et al. Combined pulmonary fibrosis and emphysema in systemic sclerosis: A syndrome associated with heavy morbidity and mortality. Semin Arthritis Rheum 2019;49:98-104.

16. Lee SH, Park JS, Kim SY, Kim DS, Kim YW, Chung MP, et al. Clinical features and prognosis of patients with idiopathic pulmonary fibrosis and chronic obstructive pulmonary disease. Int J Tuberc Lung Dis 2019;23:678-84.

17. Ryerson CJ, Hartman T, Elicker BM, Ley B, Lee JS, Abbritti $M$, et al. Clinical features and outcomes in combined pulmonary fibrosis and emphysema in idiopathic pulmonary fibrosis. Chest 2013;144:234-40.

18. Yoon HY, Kim TH, Seo JB, Lee SM, Lim S, Lee HN, et al. Effects of emphysema on physiological and prognostic characteristics of lung function in idiopathic pulmonary fibrosis. Respirology 2019;24:55-62.

19. Jacob J, Song JW, Yoon HY, Cross G, Barnett J, Woo WL, et al. Prevalence and Effects of Emphysema in Never-Smokers with Rheumatoid Arthritis Interstitial Lung Disease. EBioMedicine 2018;28:303-10.

20. Putman RK, Hatabu H, Araki T, Gudmundsson G, Gao W, Nishino M, et al. Association Between Interstitial Lung Abnormalities and All-Cause Mortality. Jama 2016;315:672-81.

21. Washko GR, Hunninghake GM, Fernandez IE, Nishino M, Okajima Y, Yamashiro T, et al. Lung volumes and emphysema in smokers with interstitial lung abnormalities. N Engl J Med 2011;364:897-906.

22. Ash SY, Harmouche R, Ross JC, Diaz AA, Rahaghi FN, Vegas Sanchez-Ferrero G, et al. Interstitial Features at Chest CT Enhance the Deleterious Effects of Emphysema in the COPDGene Cohort. Radiology 2018;288:600-9.

23. Ohgiya $M$, Matsui $H$, Tamura A, Kato $T$, Akagawa $S$, Ohta K. The Evaluation of Interstitial Abnormalities in Group B of the 2011 Global Initiative for Chronic Obstructive Lung Disease (GOLD) Classification of Chronic Obstructive Pulmonary Disease (COPD). Intern Med 2017;56:2711-7. 
24. Amariei DE, Dodia N, Deepak J, Hines SE, Galvin JR, Atamas SP, et al. Combined Pulmonary Fibrosis and Emphysema: Pulmonary Function Testing and a Pathophysiology Perspective. Medicina (Kaunas) 2019;55.

25. Bédard Méthot $D$, Leblanc É, Lacasse Y. Meta-analysis of Gastroesophageal Reflux Disease and Idiopathic Pulmonary Fibrosis. Chest 2019;155:33-43.

26. Tzouvelekis A, Zacharis G, Oikonomou A, Mikroulis D, Margaritopoulos G, Koutsopoulos A, et al. Increased incidence of autoimmune markers in patients with combined pulmonary fibrosis and emphysema. BMC Pulm Med 2013;13:31.

27. Hanaoka $M$, Ito $M$, Droma $Y$, Ushiki $A$, Kitaguchi $Y$, Yasuo $M$, et al. Comparison of gene expression profiling between lung fibrotic and emphysematous tissues sampled from patients with combined pulmonary fibrosis and emphysema. Fibrogenesis Tissue Repair 2012;5:17.

28. Papaioannou Al, Kostikas K, Manali ED, Papadaki G, Roussou A, Kolilekas L, et al. Combined pulmonary fibrosis and emphysema: The many aspects of a cohabitation contract. Respir Med 2016;117:14-26.

29. Ding $Y, L i ~ Q, ~ W u ~ C$, Wang $W$, Zhao J, Feng $Q$, et al. TERT gene polymorphisms are associated with chronic obstructive pulmonary disease risk in the Chinese Li population. Mol Genet Genomic Med 2019;7:e773.

30. Hirano $C$, Ohshimo $S$, Horimasu $Y$, Iwamoto $H$, Fujitaka $K$, Hamada $H$, et al. FAM13A polymorphism as a prognostic factor in patients with idiopathic pulmonary fibrosis. Respir Med 2017;123:105-9.

31. Wang B, Liang B, Yang J, Xiao J, Ma C, Xu S, et al. Association of FAM13A polymorphisms with COPD and COPD-related phenotypes in Han Chinese. Clin Biochem 2013;46:1683-8.

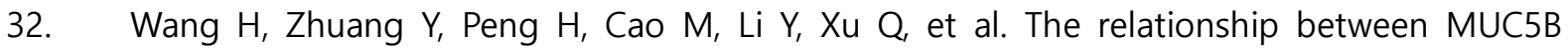
promoter, TERT polymorphisms and telomere lengths with radiographic extent and survival in a Chinese IPF cohort. Sci Rep 2019;9:15307.

33. Guzmán-Vargas J, Ambrocio-Ortiz E, Pérez-Rubio G, Ponce-Gallegos MA, HernándezZenteno RJ, Mejía M, et al. Differential Genomic Profile in TERT, DSP, and FAM13A Between COPD Patients With Emphysema, IPF, and CPFE Syndrome. Front Med (Lausanne) 2021;8:725144.

34. Cottin V, Reix P, Khouatra C, Thivolet-Béjui F, Feldmann D, Cordier JF. Combined pulmonary fibrosis and emphysema syndrome associated with familial SFTPC mutation. Thorax 2011;66:918-9.

35. Epaud R, Delestrain C, Louha M, Simon S, Fanen P, Tazi A. Combined pulmonary fibrosis and emphysema syndrome associated with ABCA3 mutations. Eur Respir J 2014;43:638-41.

36. Kinjo $T$, Kitaguchi $Y$, Droma $Y$, Yasuo $M$, Wada $Y$, Ueno $F$, et al. The Gly82Ser mutation in AGER contributes to pathogenesis of pulmonary fibrosis in combined pulmonary fibrosis and emphysema (CPFE) in Japanese patients. Sci Rep 2020;10:12811.

37. Cornwell WD, Kim C, Lastra AC, Dass $C$, Bolla $S$, Wang $H$, et al. Inflammatory signature in 
lung tissues in patients with combined pulmonary fibrosis and emphysema. Biomarkers 2019;24:232-9.

38. Xu L, Bian W, Gu XH, Shen C. Differing Expression of Cytokines and Tumor Markers in Combined Pulmonary Fibrosis and Emphysema Compared to Emphysema and Pulmonary Fibrosis. Copd 2017; 14:245-50.

39. Papaioannou Al, Kostikas K, Manali ED, Papadaki G, Roussou A, Spathis A, et al. Serum Levels of Surfactant Proteins in Patients with Combined Pulmonary Fibrosis and Emphysema (CPFE). PLoS One 2016;11:e0157789.

40. Tasaka S, Mizoguchi K, Funatsu Y, Namkoong H, Yamasawa W, Ishii M, et al. Cytokine profile of bronchoalveolar lavage fluid in patients with combined pulmonary fibrosis and emphysema. Respirology 2012;17:814-20.

41. Chiba S, Ohta H, Abe K, Hisata S, Ohkouchi S, Hoshikawa Y, et al. The Diagnostic Value of the Interstitial Biomarkers KL-6 and SP-D for the Degree of Fibrosis in Combined Pulmonary Fibrosis and Emphysema. Pulm Med 2012;2012:492960.

42. Jiang $Y$, Luo $Q$, Han $Q$, Huang J, Ou $Y$, Chen $M$, et al. Sequential changes of serum KL-6 predict the progression of interstitial lung disease. J Thorac Dis 2018;10:4705-14.

43. Yokoyama A, Kondo K, Nakajima $M$, Matsushima $T$, Takahashi $T$, Nishimura $M$, et al. Prognostic value of circulating KL-6 in idiopathic pulmonary fibrosis. Respirology 2006;11:164-8.

44. Satoh $H$, Kurishima $K$, Ishikawa $H$, Ohtsuka M. Increased levels of KL-6 and subsequent mortality in patients with interstitial lung diseases. J Intern Med 2006;260:429-34.

45. Kohno N, Kyoizumi S, Awaya Y, Fukuhara H, Yamakido M, Akiyama M. New serum indicator of interstitial pneumonitis activity. Sialylated carbohydrate antigen KL-6. Chest 1989;96:6873.

46. Chiba S, Tsuchiya $K$, Nukui $Y$, Sema $M$, Tamaoka $M$, Sumi $Y$, et al. Interstitial changes in asthma-COPD overlap syndrome. Clin Respir J 2017;11:1024-31.

47. Kishaba T, Shimaoka Y, Fukuyama H, Yoshida K, Tanaka M, Yamashiro S, et al. A cohort study of mortality predictors and characteristics of patients with combined pulmonary fibrosis and emphysema. BMJ Open 2012;2.

48. Ohshimo S, Ishikawa N, Horimasu Y, Hattori N, Hirohashi N, Tanigawa K, et al. Baseline KL6 predicts increased risk for acute exacerbation of idiopathic pulmonary fibrosis. Respir Med 2014;108:1031-9.

49. Wong AW, Liang J, Cottin V, Ryerson CJ. Diagnostic Features in Combined Pulmonary Fibrosis and Emphysema: A Systematic Review. Ann Am Thorac Soc 2020;17:1333-6.

50. Lee $\mathrm{CH}$, Kim HJ, Park CM, Lim KY, Lee JY, Kim DJ, et al. The impact of combined pulmonary fibrosis and emphysema on mortality. Int J Tuberc Lung Dis 2011;15:1111-6.

51. Suzuki M, Kawata N, Abe M, Yokota H, Anazawa R, Matsuura $Y$, et al. Objective quantitative multidetector computed tomography assessments in patients with combined pulmonary fibrosis with emphysema: Relationship with pulmonary function and clinical 
events. PLoS One 2020;15:e0239066.

52. Cottin V. The impact of emphysema in pulmonary fibrosis. Eur Respir Rev 2013;22:153-7.

53. Matsuoka S, Yamashiro T, Matsushita S, Fujikawa A, Kotoku A, Yagihashi K, et al. Morphological disease progression of combined pulmonary fibrosis and emphysema: comparison with emphysema alone and pulmonary fibrosis alone. J Comput Assist Tomogr 2015;39:153-9.

54. Kitaguchi Y, Fujimoto K, Hanaoka M, Kawakami S, Honda T, Kubo K. Clinical characteristics of combined pulmonary fibrosis and emphysema. Respirology 2010;15:265-71.

55. Inomata M, Ikushima S, Awano N, Kondoh K, Satake K, Masuo M, et al. An autopsy study of combined pulmonary fibrosis and emphysema: correlations among clinical, radiological, and pathological features. BMC Pulm Med 2014;14:104.

56. Sugino K, Ishida F, Kikuchi N, Hirota N, Sano G, Sato K, et al. Comparison of clinical characteristics and prognostic factors of combined pulmonary fibrosis and emphysema versus idiopathic pulmonary fibrosis alone. Respirology 2014;19:239-45.

57. Jankowich MD, Polsky $M$, Klein $M$, Rounds $S$. Heterogeneity in combined pulmonary fibrosis and emphysema. Respiration 2008;75:411-7.

58. Brillet PY, Cottin V, Letoumelin P, Landino F, Brauner MW, Valeyre D, et al. [Combined apical emphysema and basal fibrosis syndrome (emphysema/fibrosis syndrome): CT imaging features and pulmonary function tests]. J Radiol 2009;90:43-51.

59. Sakai $F$, Tominaga J, Kaga A, Usui $Y$, Kanazawa $M$, Ogura $T$, et al. Imaging diagnosis of interstitial pneumonia with emphysema (combined pulmonary fibrosis and emphysema). Pulm Med 2012;2012:816541.

60. Abi Khalil S, Gourdier AL, Aoun N, Nedelcu C, El Rai S, Moubarak E, et al. [Cystic and cavitary lesions of the lung: imaging characteristics and differential diagnosis]. J Radiol 2010;91:465-73.

61. Swigris JJ. Towards a refined definition of combined pulmonary fibrosis and emphysema. Respirology 2019;24:9-10.

62. Jiang $\mathrm{CG}, \mathrm{Fu} \mathrm{Q}$, Zheng $\mathrm{CM}$. Prognosis of combined pulmonary fibrosis and emphysema: comparison with idiopathic pulmonary fibrosis alone. Ther Adv Respir Dis 2019;13:1753466619888119.

63. Jankowich MD, Rounds S. Combined pulmonary fibrosis and emphysema alters physiology but has similar mortality to pulmonary fibrosis without emphysema. Lung 2010;188:365-73.

64. Jacob J, Bartholmai BJ, Rajagopalan S, Kokosi M, Maher TM, Nair A, et al. Functional and prognostic effects when emphysema complicates idiopathic pulmonary fibrosis. Eur Respir J 2017;50.

65. Mejía M, Carrillo G, Rojas-Serrano J, Estrada A, Suárez T, Alonso D, et al. Idiopathic pulmonary fibrosis and emphysema: decreased survival associated with severe pulmonary arterial hypertension. Chest 2009;136:10-5.

66. Zhang L, Zhang C, Dong F, Song Q, Chi F, Liu L, et al. Combined pulmonary fibrosis and 
emphysema: a retrospective analysis of clinical characteristics, treatment and prognosis. BMC Pulm Med 2016;16:137.

67. Kohashi Y, Arai T, Sugimoto C, Tachibana K, Akira M, Kitaichi M, et al. Clinical Impact of Emphysema Evaluated by High-Resolution Computed Tomography on Idiopathic Pulmonary Fibrosis Diagnosed by Surgical Lung Biopsy. Respiration 2016;92:220-8.

68. Choi SH, Lee HY, Lee KS, Chung MP, Kwon OJ, Han J, et al. The value of CT for disease detection and prognosis determination in combined pulmonary fibrosis and emphysema (CPFE). PLoS One 2014;9:e107476.

69. Todd NW, Jeudy J, Lavania S, Franks TJ, Galvin JR, Deepak J, et al. Centrilobular emphysema combined with pulmonary fibrosis results in improved survival. Fibrogenesis Tissue Repair 2011;4:6.

70. Kurashima K, Takayanagi N, Tsuchiya N, Kanauchi T, Ueda M, Hoshi T, et al. The effect of emphysema on lung function and survival in patients with idiopathic pulmonary fibrosis. Respirology 2010;15:843-8.

71. Jacob J, Bartholmai BJ, Rajagopalan S, Karwoski R, Nair A, Walsh SLF, et al. Likelihood of pulmonary hypertension in patients with idiopathic pulmonary fibrosis and emphysema. Respirology 2018;23:593-9.

72. Lin $\mathrm{H}$, Jiang $\mathrm{S}$. Combined pulmonary fibrosis and emphysema (CPFE): an entity different from emphysema or pulmonary fibrosis alone. J Thorac Dis 2015;7:767-79.

73. Ikuyama $Y$, Ushiki A, Kosaka M, Akahane J, Mukai Y, Araki T, et al. Prognosis of patients with acute exacerbation of combined pulmonary fibrosis and emphysema: a retrospective single-centre study. BMC Pulm Med 2020;20:144.

74. Zantah M, Dotan Y, Dass C, Zhao H, Marchetti N, Criner GJ. Acute exacerbations of COPD versus IPF in patients with combined pulmonary fibrosis and emphysema. Respir Res 2020;21:164.

75. Cottin V, Le Pavec J, Prévot G, Mal H, Humbert M, Simonneau G, et al. Pulmonary hypertension in patients with combined pulmonary fibrosis and emphysema syndrome. Eur Respir J 2010;35:105-11.

76. Malli F, Papakosta D, Antoniou K, Dimadi M, Polychronopoulos V, Malagari K, et al. Combined pulmonary fibrosis and emphysema characteristics in a Greek cohort. ERJ Open Res 2019;5.

77. Jankowich MD, Rounds SIS. Combined pulmonary fibrosis and emphysema syndrome: a review. Chest 2012;141:222-31.

78. Kwak N, Park CM, Lee J, Park YS, Lee SM, Yim J, et al. Lung cancer risk among patients with combined pulmonary fibrosis and emphysema. Respir Med 2014;108:524-30.

79. Oh JY, Lee YS, Min KH, Hur GY, Lee SY, Kang KH, et al. Presence of lung cancer and high gender, age, and physiology score as predictors of acute exacerbation in combined pulmonary fibrosis and emphysema: A retrospective study. Medicine (Baltimore) 2018;97:e11683. 
80. Moon SW, Park MS, Kim YS, Jang J, Lee JH, Lee CT, et al. Combined pulmonary fibrosis and emphysema and idiopathic pulmonary fibrosis in non-small cell lung cancer: impact on survival and acute exacerbation. BMC Pulm Med 2019;19:177.

81. Nemoto $M$, Nei $Y$, Bartholmai B, Yoshida $K$, Matsui $H$, Nakashita $T$, et al. Automated computed tomography quantification of fibrosis predicts prognosis in combined pulmonary fibrosis and emphysema in a real-world setting: a single-centre, retrospective study. Respir Res 2020;21:275.

82. Bolaki M, Antoniou KM. Combined Pulmonary Fibrosis and Emphysema. Semin Respir Crit Care Med 2020;41:177-83.

83. Jacob J, Bartholmai BJ, Rajagopalan S, van Moorsel CHM, van Es HW, van Beek FT, et al. Predicting Outcomes in Idiopathic Pulmonary Fibrosis Using Automated Computed Tomographic Analysis. Am J Respir Crit Care Med 2018;198:767-76.

84. Fleming $H$, Clifford SM, Haughey A, MacDermott $R$, McVeigh N, Healy GM, et al. Differentiating combined pulmonary fibrosis and emphysema from pure emphysema: utility of late gadolinium-enhanced MRI. Eur Radiol Exp 2020;4:61.

85. Araki T, Putman RK, Hatabu H, Gao W, Dupuis J, Latourelle JC, et al. Development and Progression of Interstitial Lung Abnormalities in the Framingham Heart Study. Am J Respir Crit Care Med 2016;194:1514-22.

86. Hunninghake GM. Interstitial lung abnormalities: erecting fences in the path towards advanced pulmonary fibrosis. Thorax 2019;74:506-11.

87. Hobbs BD, Putman RK, Araki T, Nishino M, Gudmundsson G, Gudnason V, et al. Overlap of Genetic Risk between Interstitial Lung Abnormalities and Idiopathic Pulmonary Fibrosis. Am J Respir Crit Care Med 2019;200:1402-13.

88. Feldhaus FW, Theilig DC, Hubner RH, Kuhnigk JM, Neumann K, Doellinger F. Quantitative CT analysis in patients with pulmonary emphysema: is lung function influenced by concomitant unspecific pulmonary fibrosis? Int J Chron Obstruct Pulmon Dis 2019;14:1583-93.

89. Ono $M$, Kobayashi $S$, Hanagama $M$, Ishida $M$, Sato $H$, Makiguchi $T$, et al. Clinical characteristics of Japanese patients with chronic obstructive pulmonary disease (COPD) with comorbid interstitial lung abnormalities: A cross-sectional study. PLoS One 2020;15:e0239764.

90. WHO Coronavirus (COVID-19) Dashboard. Available from: https://covid19.who.int/.

91. Yang J, Zheng Y, Gou X, Pu K, Chen Z, Guo Q, et al. Prevalence of comorbidities and its effects in patients infected with SARS-CoV-2: a systematic review and meta-analysis. Int J Infect Dis 2020;94:91-5.

92. Information note on COVID-19 and NCDs : WHO. Available from: https://www.who.int/publications/m/item/covid-19-and-ncds.

93. Docherty $A B$, Harrison EM, Green $C A$, Hardwick HE, Pius R, Norman $L$, et al. Features of 20 133 UK patients in hospital with covid-19 using the ISARIC WHO Clinical Characterisation 
Protocol: prospective observational cohort study. Bmj 2020;369:m1985.

94. Sanchez-Ramirez DC, Mackey D. Underlying respiratory diseases, specifically COPD, and smoking are associated with severe COVID-19 outcomes: A systematic review and metaanalysis. Respir Med 2020;171:106096.

95. Drake TM, Docherty AB, Harrison EM, Quint JK, Adamali H, Agnew $S$, et al. Outcome of Hospitalization for COVID-19 in Patients with Interstitial Lung Disease. An International Multicenter Study. Am J Respir Crit Care Med 2020;202:1656-65.

96. Esposito AJ, Menon AA, Ghosh AJ, Putman RK, Fredenburgh LE, El-Chemaly SY, et al. Increased Odds of Death for Patients with Interstitial Lung Disease and COVID-19: A CaseControl Study. Am J Respir Crit Care Med 2020;202:1710-3.

97. Gallay L, Uzunhan Y, Borie R, Lazor R, Rigaud P, Marchand-Adam S, et al. Risk Factors for Mortality after COVID-19 in Patients with Preexisting Interstitial Lung Disease. Am J Respir Crit Care Med 2021;203:245-9.

98. Graziani D, Soriano JB, Del Rio-Bermudez C, Morena D, Díaz T, Castillo $M$, et al. Characteristics and Prognosis of COVID-19 in Patients with COPD. J Clin Med 2020;9.

99. Clift AK, Coupland CAC, Keogh RH, Diaz-Ordaz K, Williamson E, Harrison EM, et al. Living risk prediction algorithm (QCOVID) for risk of hospital admission and mortality from coronavirus 19 in adults: national derivation and validation cohort study. Bmj 2020;371:m3731.

100. Hippisley-Cox J, Young D, Coupland C, Channon KM, Tan PS, Harrison DA, et al. Risk of severe COVID-19 disease with ACE inhibitors and angiotensin receptor blockers: cohort study including 8.3 million people. Heart 2020;106:1503-11.

101. Calmes D, Graff S, Maes N, Frix AN, Thys M, Bonhomme O, et al. Asthma and COPD Are Not Risk Factors for ICU Stay and Death in Case of SARS-CoV2 Infection. J Allergy Clin Immunol Pract 2021;9:160-9.

102. Gupta S, Hayek SS, Wang W, Chan L, Mathews KS, Melamed ML, et al. Factors Associated With Death in Critically III Patients With Coronavirus Disease 2019 in the US. JAMA Intern Med 2020;180:1436-47.

103. Ioannou GN, Locke E, Green P, Berry K, O'Hare AM, Shah JA, et al. Risk Factors for Hospitalization, Mechanical Ventilation, or Death Among 10131 US Veterans With SARSCoV-2 Infection. JAMA Netw Open 2020;3:e2022310.

104. Chae KJ, Jin GY, Han YM, Kim YS, Chon SB, Lee YS, et al. Prevalence and progression of combined pulmonary fibrosis and emphysema in asymptomatic smokers: A case-control study. Eur Radiol 2015;25:2326-34.

105. Tashkin DP. Smoking Cessation in Chronic Obstructive Pulmonary Disease. Semin Respir Crit Care Med 2015;36:491-507.

106. Aduen JF, Zisman DA, Mobin SI, Venegas C, Alvarez F, Biewend M, et al. Retrospective study of pulmonary function tests in patients presenting with isolated reduction in singlebreath diffusion capacity: implications for the diagnosis of combined obstructive and 
restrictive lung disease. Mayo Clin Proc 2007;82:48-54.

107. Ando K, Sekiya M, Tobino K, Takahashi K. Relationship between quantitative CT metrics and pulmonary function in combined pulmonary fibrosis and emphysema. Lung 2013;191:585-91.

108. Kitaguchi Y, Fujimoto K, Hayashi R, Hanaoka M, Honda T, Kubo K. Annual changes in pulmonary function in combined pulmonary fibrosis and emphysema: over a 5-year follow-up. Respir Med 2013;107:1986-92.

109. Tzilas V, Bouros D. Combined Pulmonary Fibrosis and Emphysema, a clinical review. COPD Research and Practice 2016;2:2.

110. Schmidt SL, Nambiar AM, Tayob N, Sundaram B, Han MK, Gross BH, et al. Pulmonary function measures predict mortality differently in IPF versus combined pulmonary fibrosis and emphysema. Eur Respir J 2011;38:176-83.

111. Young KA, Strand $M$, Ragland MF, Kinney GL, Austin EE, Regan EA, et al. Pulmonary Subtypes Exhibit Differential Global Initiative for Chronic Obstructive Lung Disease Spirometry Stage Progression: The COPDGene ${ }^{\circledR}$ Study. Chronic Obstr Pulm Dis 2019;6:414-29.

112. Spruit MA, Singh SJ, Garvey C, ZuWallack R, Nici L, Rochester C, et al. An official American Thoracic Society/European Respiratory Society statement: key concepts and advances in pulmonary rehabilitation. Am J Respir Crit Care Med 2013;188:e13-64.

113. Zeng $Y$, Jiang $F$, Chen $Y$, Chen $P$, Cai $S$. Exercise assessments and trainings of pulmonary rehabilitation in COPD: a literature review. Int J Chron Obstruct Pulmon Dis 2018;13:201323.

114. Holland AE, Hill CJ, Conron M, Munro P, McDonald CF. Short term improvement in exercise capacity and symptoms following exercise training in interstitial lung disease. Thorax 2008;63:549-54.

115. Nishiyama O, Kondoh Y, Kimura T, Kato K, Kataoka K, Ogawa T, et al. Effects of pulmonary rehabilitation in patients with idiopathic pulmonary fibrosis. Respirology 2008;13:394-9.

116. Kozu R, Senjyu H, Jenkins SC, Mukae H, Sakamoto N, Kohno S. Differences in response to pulmonary rehabilitation in idiopathic pulmonary fibrosis and chronic obstructive pulmonary disease. Respiration 2011;81:196-205.

117. Holland A, Hill C. Physical training for interstitial lung disease. Cochrane Database Syst Rev 2008:Cd006322.

118. Huppmann P, Sczepanski B, Boensch M, Winterkamp S, Schönheit-Kenn U, Neurohr C, et al. Effects of inpatient pulmonary rehabilitation in patients with interstitial lung disease. Eur Respir J 2013;42:444-53.

119. Tomioka H, Mamesaya N, Yamashita S, Kida Y, Kaneko M, Sakai H. Combined pulmonary fibrosis and emphysema: effect of pulmonary rehabilitation in comparison with chronic obstructive pulmonary disease. BMJ Open Respir Res 2016;3:e000099.

120. Dong $F$, Zhang $Y, C$ i $F$, Song $Q$, Zhang $L$, Wang $Y$, et al. Clinical efficacy and safety of 
ICS/LABA in patients with combined idiopathic pulmonary fibrosis and emphysema. Int J Clin Exp Med 2015;8:8617-25.

121. Cottin V, Crestani B, Valeyre D, Wallaert B, Cadranel J, Dalphin JC, et al. Diagnosis and management of idiopathic pulmonary fibrosis: French practical guidelines. Eur Respir Rev 2014;23:193-214.

122. Hu PW, Ko HK, Su KC, Feng JY, Su WJ, Hsiao YH, et al. Functional parameters of small airways can guide bronchodilator use in idiopathic pulmonary fibrosis. Sci Rep 2020;10:18633.

123. Bickel S, Popler J, Lesnick B, Eid N. Impulse oscillometry: interpretation and practical applications. Chest 2014;146:841-7.

124. Choi JY, Rhee CK. Diagnosis and Treatment of Early Chronic Obstructive Lung Disease (COPD). J Clin Med 2020;9.

125. Kitaguchi $Y$, Fujimoto K, Hanaoka M, Honda T, Hotta J, Hirayama J. Pulmonary function impairment in patients with combined pulmonary fibrosis and emphysema with and without airflow obstruction. Int J Chron Obstruct Pulmon Dis 2014;9:805-11.

126. King TE, Jr., Bradford WZ, Castro-Bernardini S, Fagan EA, Glaspole I, Glassberg MK, et al. A phase 3 trial of pirfenidone in patients with idiopathic pulmonary fibrosis. N Engl J Med 2014;370:2083-92.

127. Noble PW, Albera C, Bradford WZ, Costabel U, du Bois RM, Fagan EA, et al. Pirfenidone for idiopathic pulmonary fibrosis: analysis of pooled data from three multinational phase 3 trials. Eur Respir J 2016;47:243-53.

128. Noble PW, Albera C, Bradford WZ, Costabel U, Glassberg MK, Kardatzke D, et al. Pirfenidone in patients with idiopathic pulmonary fibrosis (CAPACITY): two randomised trials. Lancet 2011;377:1760-9.

129. Richeldi L, du Bois RM, Raghu G, Azuma A, Brown KK, Costabel U, et al. Efficacy and safety of nintedanib in idiopathic pulmonary fibrosis. N Engl J Med 2014;370:2071-82.

130. Cottin V, Azuma A, Raghu G, Stansen W, Stowasser S, Schlenker-Herceg R, et al. Therapeutic effects of nintedanib are not influenced by emphysema in the INPULSIS trials. Eur Respir J 2019;53.

131. Vacchi C, Sebastiani M, Cassone G, Cerri S, Della Casa G, Salvarani C, et al. Therapeutic Options for the Treatment of Interstitial Lung Disease Related to Connective Tissue Diseases. A Narrative Review. J Clin Med 2020;9.

132. Wijsenbeek M, Cottin V. Spectrum of Fibrotic Lung Diseases. N Engl J Med 2020;383:95868.

133. Homma S, Bando M, Azuma A, Sakamoto S, Sugino K, Ishii $Y$, et al. Japanese guideline for the treatment of idiopathic pulmonary fibrosis. Respir Investig 2018;56:268-91.

134. Higginson IJ, Bausewein C, Reilly CC, Gao W, Gysels M, Dzingina M, et al. An integrated palliative and respiratory care service for patients with advanced disease and refractory breathlessness: a randomised controlled trial. Lancet Respir Med 2014;2:979-87. 
135. Brighton LJ, Miller S, Farquhar M, Booth S, Yi D, Gao W, et al. Holistic services for people with advanced disease and chronic breathlessness: a systematic review and meta-analysis. Thorax 2019;74:270-81.

136. Simon ST, Higginson IJ, Booth S, Harding R, Weingärtner V, Bausewein C. Benzodiazepines for the relief of breathlessness in advanced malignant and non-malignant diseases in adults. Cochrane Database Syst Rev 2016;10:Cd007354.

137. Ekström M, Bajwah S, Bland JM, Currow DC, Hussain J, Johnson MJ. One evidence base; three stories: do opioids relieve chronic breathlessness? Thorax 2018;73:88-90.

138. Ekström M, Nilsson F, Abernethy AA, Currow DC. Effects of opioids on breathlessness and exercise capacity in chronic obstructive pulmonary disease. A systematic review. Ann Am Thorac Soc 2015;12:1079-92.

139. Higginson IJ, Wilcock A, Johnson MJ, Bajwah S, Lovell N, Yi D, et al. Randomised, doubleblind, multicentre, mixed-methods, dose-escalation feasibility trial of mirtazapine for better treatment of severe breathlessness in advanced lung disease (BETTER-B feasibility). Thorax 2020;75:176-9.

140. Smoller JW, Pollack MH, Systrom D, Kradin RL. Sertraline effects on dyspnea in patients with obstructive airways disease. Psychosomatics 1998;39:24-9.

141. Lacasse $Y$, Beaudoin L, Rousseau L, Maltais F. Randomized trial of paroxetine in end-stage COPD. Monaldi Arch Chest Dis 2004;61:140-7.

142. Eiser N, Harte R, Spiros K, Phillips C, Isaac MT. Effect of treating depression on quality-oflife and exercise tolerance in severe COPD. Copd 2005;2:233-41.

143. Currow DC, Ekström M, Louw S, Hill J, Fazekas B, Clark K, et al. Sertraline in symptomatic chronic breathlessness: a double blind, randomised trial. Eur Respir J 2019;53.

144. Nathan SD, Barbera JA, Gaine SP, Harari S, Martinez FJ, Olschewski H, et al. Pulmonary hypertension in chronic lung disease and hypoxia. Eur Respir J 2019;53.

145. Kusaka K, Morio Y, Kimura Y, Takeda K, Kawashima M, Masuda K, et al. Improvement of pulmonary arterial compliance by pulmonary vasodilator in pulmonary hypertension from combined pulmonary fibrosis and emphysema. Respir Med Case Rep 2019;28:100940.

146. Straub G, Caviezel C, Frauenfelder T, Bloch KE, Franzen D. Successful lung volume reduction surgery in combined pulmonary emphysema and fibrosis without bodyplethysmographic hyperinflation-a case report. J Thorac Dis 2018;10:S2830-s4.

147. Takahashi T, Terada Y, Pasque MK, Liu J, Byers DE, Witt CA, et al. Clinical Features and Outcomes of Combined Pulmonary Fibrosis and Emphysema After Lung Transplantation. Chest 2021;160:1743-50. 


\section{Tables}

Table 1. Prognosis of CPFE and COPD with ILA

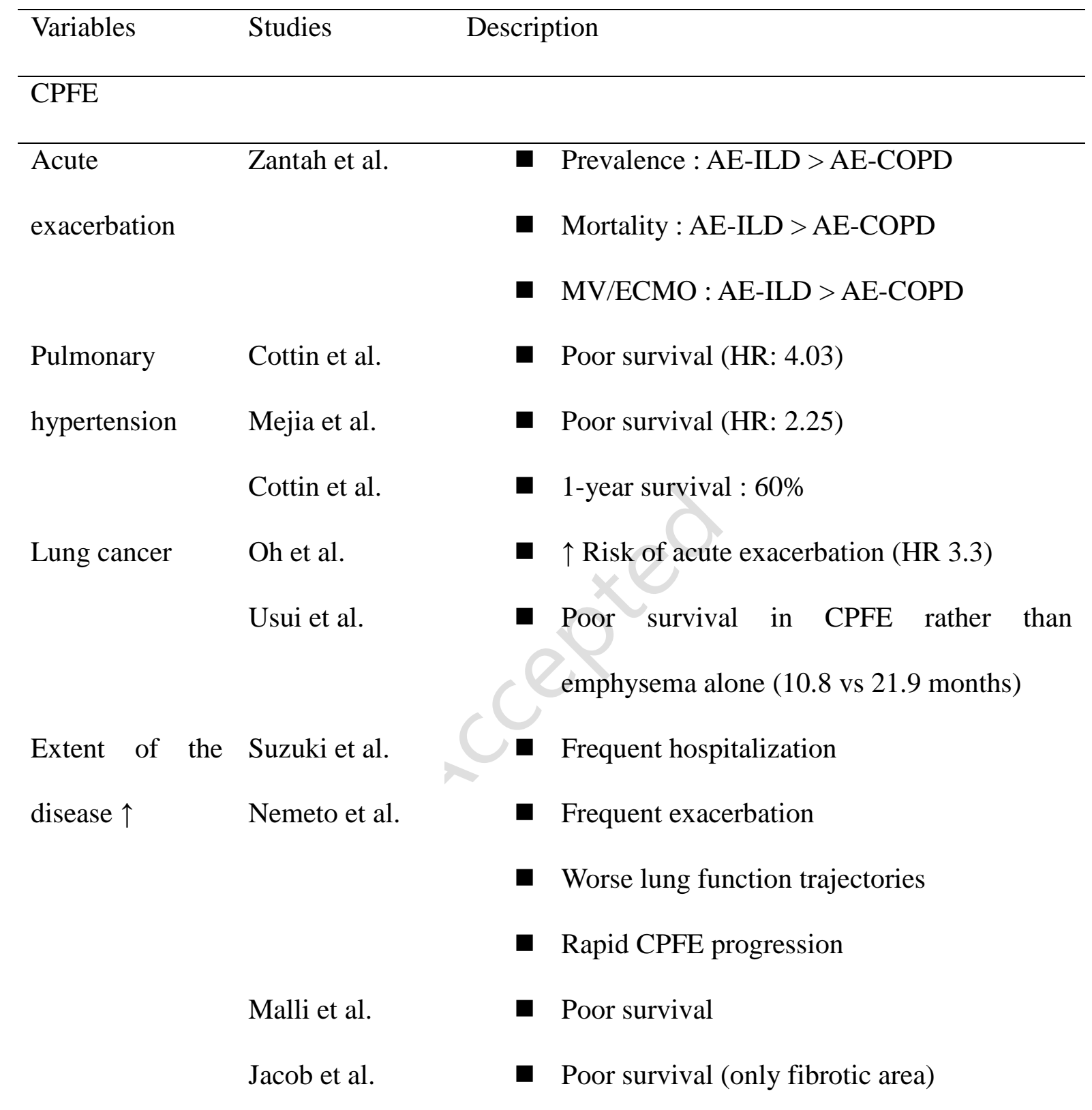

COPD

Presence of ILA Putman et al.

Higher mortality (HR 2.7)

Ash et al.

- $\uparrow$ FEV1,$\downarrow$ DLCO/6MWT/SGRQ/mortality

Onon et al.

- Lower exacerbation 
Table 2. Potential pharmacologic treatments for CPFE

\begin{tabular}{|c|c|c|}
\hline Studies & Drugs & Description \\
\hline Dong et al. & ICS/LABA & $\begin{array}{ll}\text { - } & \uparrow \mathrm{FEV} 1 \%, \mathrm{FVC} \%, \mathrm{DLCO} \% \text { in } \mathrm{CPFE} \\
\text { - } & \text { Radiological improvement in CPFE } \\
\text { - } & \downarrow \text { Exacerbation rate in CPFE }\end{array}$ \\
\hline Hu et al. & Bronchodilators & 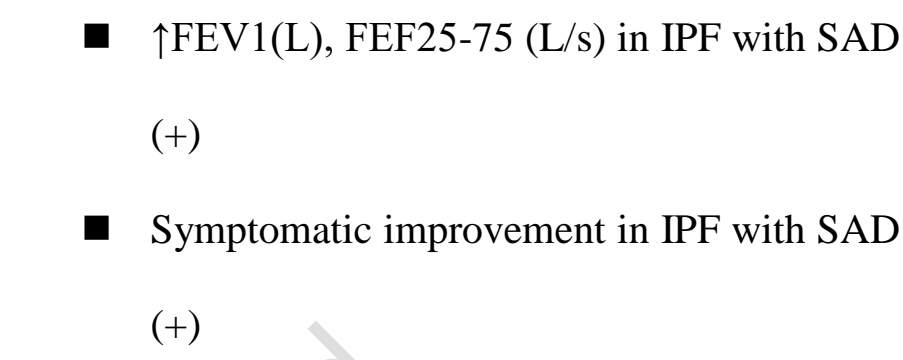 \\
\hline Noble et al. & Pirfenidone & $\begin{array}{l}\downarrow \text { FVC decline rate in FEV1/FVC } 0.70-0.80 \\
\text { with IPF }\end{array}$ \\
\hline Cottin et al. & Nintedanib & $\begin{array}{l}\downarrow \text { FVC decline rate in FEV1/FVC 0.70-0.80 } \\
\text { with IPF }\end{array}$ \\
\hline Higginson et al. & Mirtazepine & $\begin{array}{l}\text { - } \downarrow \text { Breathlessness in advanced chronic lung } \\
\text { diseases }\end{array}$ \\
\hline Tadalafil & Tadalafil & $\begin{array}{l}\text { - } \uparrow \text { pulmonary arterial compliance, exercise } \\
\text { capacity in CPFE with } \mathrm{PH}\end{array}$ \\
\hline
\end{tabular}


Figure legends

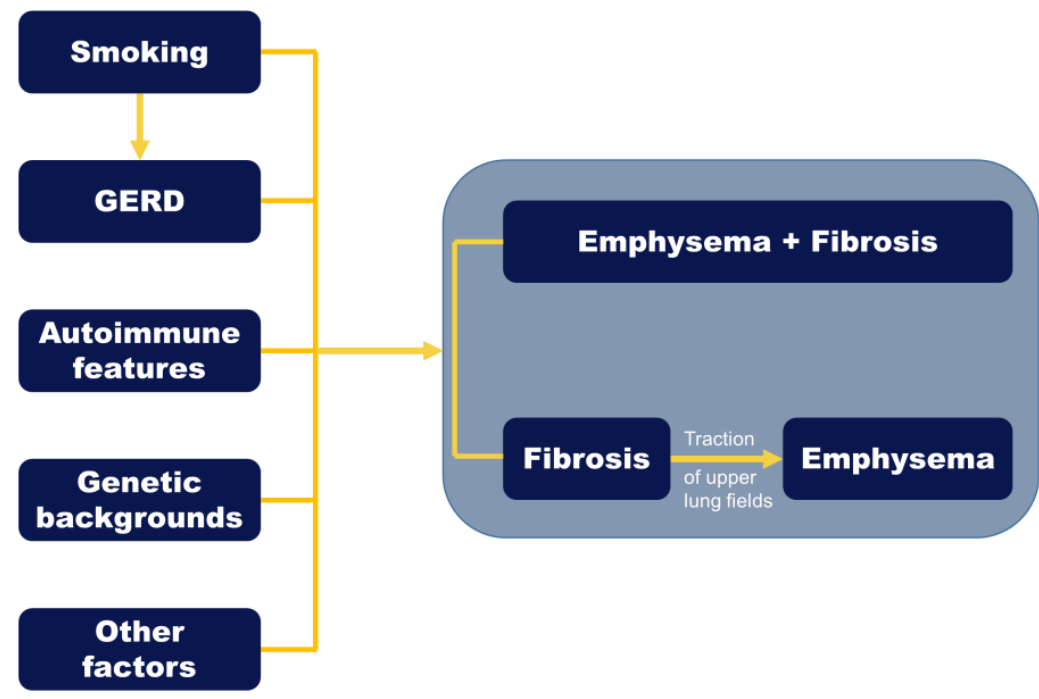

Figure 1. Pathophysiology of CPFE 


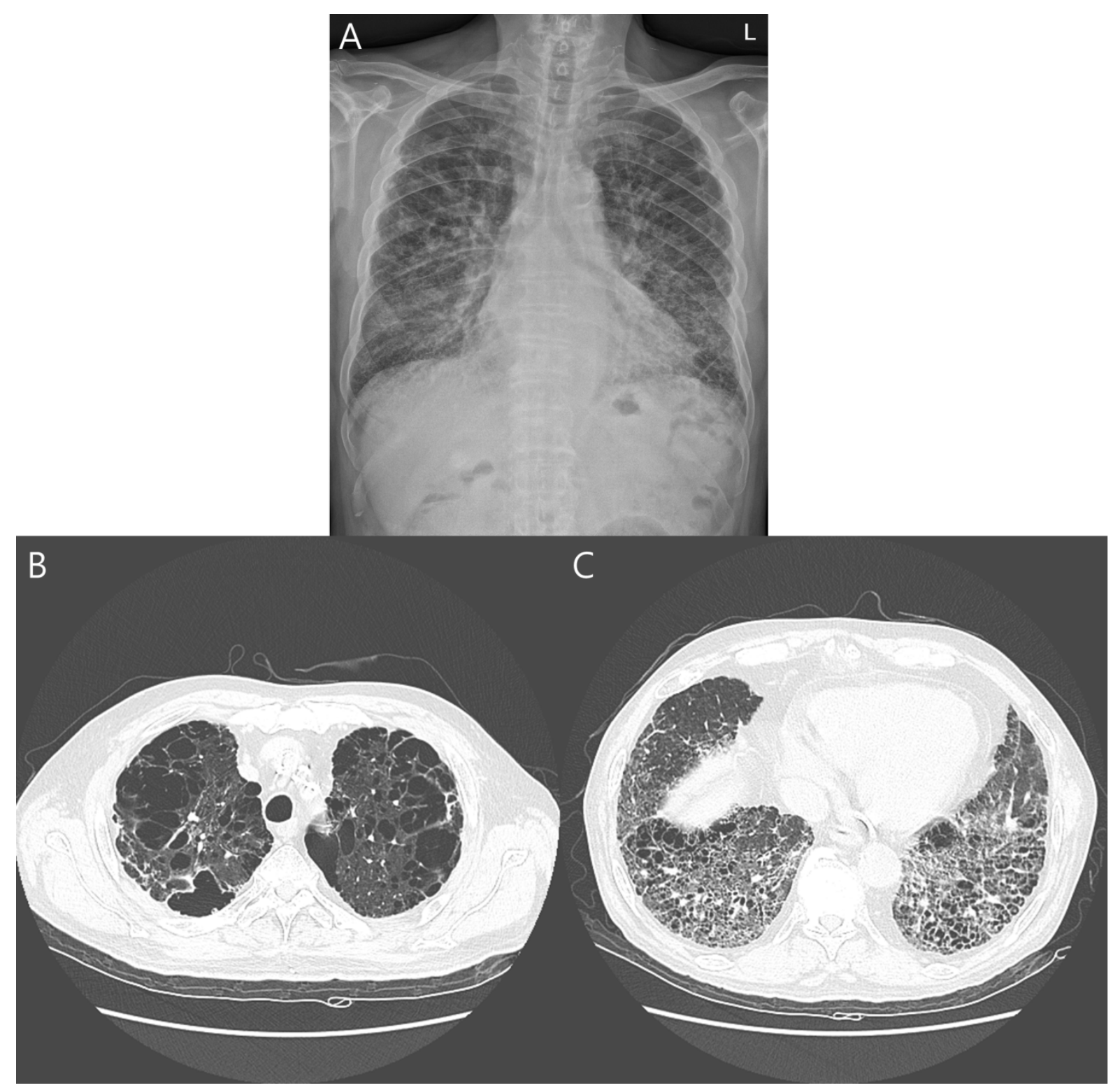

Figure 2. Images from 73-year old male smoker with CPFE. A, Chest radiography. B and C, CT image. 


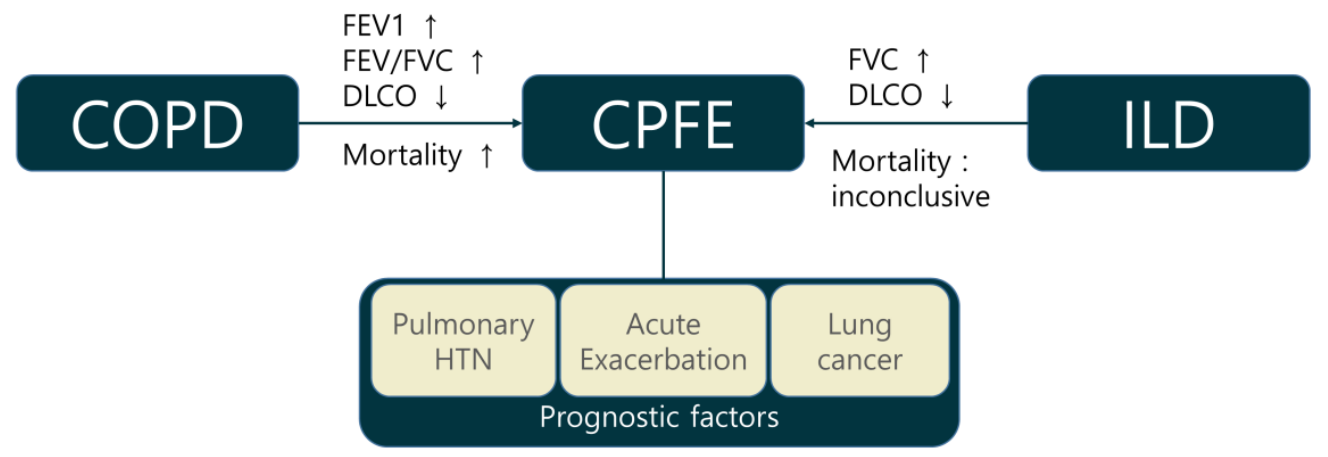

Figure 3. Clinical implications and prognostic factors of CPFE

The English in this document has been checked by at least two professional editors, both native speakers of English. For a certificate, please see:

http://www.textcheck.com/certificate/UwYETr 


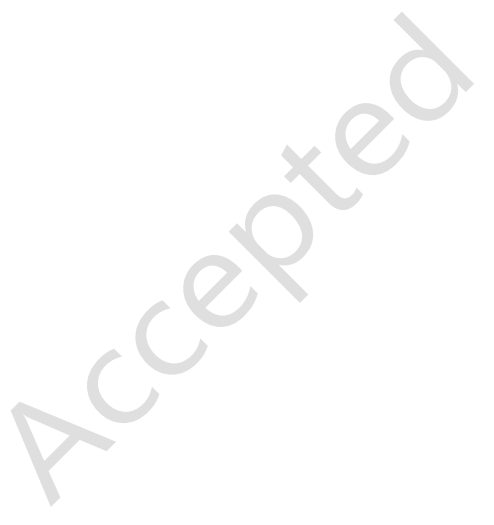

